\title{
Clinical assessment and nutritional awareness among school going adolescent girls of Kanpur (U.P.)
}

\author{
Rakhee Katiyar and Gurmeet Kaur
}

The present study was conducted in Kanpur (U.P.) among 400 school going adolescent girls (13-19 years) for finding out their clinical problems, general health status and nutritional awareness. From the investigation conducted it was observed that 97.2 per cent school going adolescent girls were suffering from problems of hair; 43 per cent teeth, 36.5 per cent nails, 31.5 per cent skin, 30.7 per cent lips and tongue, 24 per cent eyes and 13.5 per cent from problems related to gums. Regarding their health status, about 78 per cent girls were suffering from general health problems like constipation, acidity, headache etc. Irregular menstrual cycle was reported by 35.5 per cent of girls and extra hair growth by 17.3 per cent of girls. Only 9.3 per cent girls were aware of their haemoglobin level and 29.5 per cent of their blood group. De worming course and vaccination was done by 12.3 per cent and 58.5 per cent adolescent girls, respectively. Knowledge that egg yolk is rich in cholesterol was reported by only 16.5 per cent of girls, similarly only 27.3 per cent knew that yellow fruits and vegetables are rich sources of vitamin A. Awareness of fats restriction for preventing heart problems and obesity was found only in 34.8 per cent of girls. Less than fifty per cent of girls were not aware of the fact that iron deficiency causes anaemia. It was observed that the health status of the girls was not good and the nutritional awareness level was also low. Therefore, it is the time to take immediate steps to overcome the problems of adolescents. Family, peer group, medical organizations, media and school together should plan and make needful efforts so that they live healthy life.

Key Words : Adolescence, Clinical observation, Nutritional awareness

How to cite this article : Katiyar, Rakhee and Kaur, Gurmeet (2019). Clinical assessment and nutritional awareness among school going adolescent girls of Kanpur (U.P.). Food Sci. Res. J., 10(2): 162-169, DOI : 10.15740/HAS/FSRJ/10.2/162-169.Copyright@ 2019: Hind Agri-Horticultural Society. 